\title{
High Trend Inflation and Passive Monetary Detours
}

\author{
Guido Ascari* \\ University of Oxford \\ University of Pavia
}

\author{
Anna Florio ${ }^{\mathrm{a}}$ \\ Politecnico di Milano \\ Alessandro Gobbi ${ }^{b}$ \\ University of Pavia
}

July 2018

\begin{abstract}
Does the long-run Taylor principle (Davig and Leeper, 2007) hold when both monetary and fiscal policies can switch and there is positive trend inflation? We find that with high trend inflation passive monetary detours are no longer possible, whatever fiscal policy is in place. This has important policy implications in terms of flexibility and monetary-fiscal authorities coordination.
\end{abstract}

Keywords: trend inflation, monetary-fiscal policy interactions, Markov-switching, determinacy. JEL classification: E52, E63.

(c) 2018. This manuscript version is made available under the CC-BY-NC-ND 4.0 license http:// creativecommons.org/licenses/by-nc-nd/4.0/

This is a pre-copyedited, author-produced version of an article accepted for publication in Economics Letters following peer review. The version of record (Economics Letters, Volume 172, November 2018, Pages 138-142) is available online at: https://doi.org/10.1016/j.econlet.2018.08.030.

\footnotetext{
${ }^{*}$ Corresponding author: Department of Economics, University of Oxford, Manor Road, Oxford OX1 3UQ, United Kingdom. E-mail address: guido.ascari@economics.ox.ac.uk

${ }^{a}$ Department of Management, Economics and Industrial Engineering, Politecnico di Milano, via Lambruschini 4/B, 20156 Milan, Italy. E-mail address: anna.florio@polimi.it

${ }^{\mathrm{b}}$ Department of Economics and Management, University of Pavia, Via San Felice 5, 27100 Pavia, Italy. E-mail address: alessandro.gobbi@unipv.it
} 


\section{Introduction}

During the Great Recession, different proposals were put forth to stimulate the major economies stuck at the zero lower bound. The most common entailed an active role for fiscal policy and the suggestion, by some influential economists, to increase the inflation target 11 We want to investigate the implications of these proposals to return to an era such as the Great Moderation characterised by a monetary led policy regime, where the central bank respects the Taylor principle while the government implements the fiscal adjustments necessary to stabilise debt.

Davig and Leeper (2007) introduce the so-called long-run Taylor principle: when fiscal policy is passive, a central bank can deviate to a passive monetary policy and still obtain determinacy if a sufficiently aggressive monetary policy is expected for the future $2^{2}$ We extend the work by Ascari et al. (2016), which studies determinacy under monetary-fiscal interactions in a Markov-switching model, to include trend inflation. That paper modifies Davig and Leeper (2007) placing fiscal policy in the foreground; here we want to check whether the long-run Taylor principle holds once trend inflation is introduced. The enlarged determinacy region found by Davig and Leeper with respect to the fixed-coefficient case could be to some extent offset by a higher level of trend inflation if, as Ascari and Ropele (2009) find, an increase in trend inflation makes the determinacy area shrink.

This paper contributes to the growing literature on monetary-fiscal policy interactions (see Davig and Leeper, 2006, 2011; Bianchi and Melosi, 2013, Bianchi and Ilut, 2017) adding determinacy analysis and trend inflation. Foerster $(2016)$, in a model with predetermined variables, considers inflation target switching that leaves determinacy unaffected thanks to full price indexation. In our model there is no indexation and even fiscal policy can switch. Florio and Gobbi (2015) use a similar model with fixed-coefficients under learning to study expectation anchoring.

We find that passive monetary detours are no longer possible when trend inflation is moderately high. And this is true both under a constantly passive fiscal regime or when fiscal policy fluctuates between active and passive. The impossibility of switching between active and passive monetary policy regimes has relevant policy implications in terms of flexibility and monetary-fiscal authorities coordination. Furthermore, we find that increasing the inflation target during the Great Recession could seriously impair the return to an expected AM/PF regime, once the passive monetary regime

\footnotetext{
${ }_{1}$ Blanchard et al. $(2010)$, Ball $(2014)$.

${ }^{2}$ We follow Leeper (1991)'s terminology. Active monetary (AM) policy arises when the central bank respects the Taylor principle. Otherwise it is passive (PM). Analogously, passive fiscal (PF) policy occurs when taxes respond sufficiently to debt to prevent its explosion; otherwise it is active (AF). In many fixed-coefficient models, a unique bounded equilibrium requires one active and one passive policy.
} 
is abandoned.

\section{$2 \quad$ Model and methodology}

Our analysis builds on Ascari et al. (2016), studying the case of positive trend inflation. We employ their non-linear version of a basic New Keynesian model with fiscal policy (see also Ascari and Ropele, 2009, Bhattarai et al. 2014):

$$
\begin{aligned}
1 & =\beta \mathbb{E}_{t}\left(\frac{Y_{t}-G}{Y_{t+1}-G} \frac{R_{t}}{\Pi_{t+1}}\right) \\
\phi_{t}\left(1-\alpha \Pi_{t}^{\theta-1}\right)^{\frac{1}{1-\theta}} & =\frac{\mu \theta(1-\alpha)^{\frac{1}{1-\theta}}}{\theta-1} Y_{t}+\alpha \beta \mathbb{E}_{t}\left[\phi_{t+1} \Pi_{t+1}^{\theta}\left(1-\alpha \Pi_{t+1}^{\theta-1}\right)^{\frac{1}{1-\theta}}\right], \\
\phi_{t} & =\frac{Y_{t}}{Y_{t}-G}+\alpha \beta \mathbb{E}_{t}\left[\Pi_{t+1}^{\theta-1} \phi_{t+1}\right] \\
\frac{b_{t}}{R_{t}} & =\frac{b_{t-1}}{\Pi_{t}}+G-\tau_{t} \\
\tau_{t} & =\tau\left(\frac{b_{t-1}}{b}\right)^{\gamma_{\tau, t}} e^{u_{\tau, t}} \\
R_{t} & =R\left(\frac{\Pi_{t}}{\Pi}\right)^{\gamma_{\pi, t}} e^{u_{m, t}}
\end{aligned}
$$

Equation (1) is a standard Euler equation for consumption, where $Y_{t}$ is output, $R_{t}$ the nominal interest rate, $\Pi_{t}$ the gross inflation rate and $G$ (exogenous and constant) government spending. (2) and (3) describe the evolution of inflation. $\phi_{t}$ is an auxiliary variable that allows to write the model recursively. Equation (4) is the government flow budget constraint, where $b_{t}=B_{t} / P_{t}$ is real government debt. Following Leeper (1991), (5) is a fiscal rule for lump-sum taxes $\tau$ that react to the deviation of lagged real debt from its steady-state level $(b)$ according to the parameter $\gamma_{\tau, t}$. Equation (6) is a simple Taylor rule whereby the central bank reacts to the deviations of current inflation from the target level (ח) according to the parameter $\gamma_{\pi, t} \cdot u_{\tau, t}$ and $u_{m, t}$ are exogenous i.i.d. fiscal and monetary policy shocks. Steady state variables are without time index. $\beta$ is the intertemporal discount factor; $\theta$ is the Dixit-Stiglitz elasticity of substitution between goods; $\mu$ is labor disutility and $\alpha$ is the Calvo probability not to re-optimise prices.

Our analysis' key parameters are $\gamma_{\pi, t}$ and $\gamma_{\tau, t}$, describing the time-varying stance of monetary and fiscal policy, respectively. We assume that they follow an underlying two-state Markov process and are equal to $\left(\gamma_{\pi, i}, \gamma_{\tau, i}\right)$ when the economy is in regime $i$, for $i=1,2$. The transition probabilities of switching between regimes $i$ and $j$ is $p_{i j}$. 


\subsection{Solution method}

As in Ascari et al. (2016), we adopt the perturbation method by Foerster et al. (2016) that retrieves all the existing minimal state variable solutions in models with Markov-switching parameters and predetermined variables. A solution is then deemed stable if it satisfies the conditions for mean square stability (Farmer et al., 2009) I $^{3}$ Therefore, a given choice for the values of $\gamma_{\pi, i}$ and $\gamma_{\tau, i}$ in the two regimes can either lead to: (i) determinacy, when a unique stable solution exists; (ii) indeterminacy, when multiple stable solutions coexist; or (iii) explosiveness, when no stable solutions exist. We perform a grid search on the policy parameters to identify the regions corresponding to these three cases.

\section{Determinacy analysis}

We concentrate on the case where one of the two regimes is AM/PF. This is the benchmark mix in the New Keynesian literature and the policy regime that characterizes the Great Moderation era. Figure 1 reports the monetary frontiers - i.e., the combinations of monetary policy coefficients in the two regimes $\left(\gamma_{\pi, 1}\right.$ and $\left.\gamma_{\pi, 2}\right)$ that deliver determinate equilibria - for different levels of trend inflation when fiscal policy stays passive in both regimes (with $\gamma_{\tau, 1}=\gamma_{\tau, 2}=0.2$ ). Remaining parameters are calibrated according to Table 1 .

\begin{tabular}{ccl} 
Table 1 & Calibration & \\
\hline Parameter & Value & Description \\
\hline$\beta$ & 0.99 & Discount factor \\
$\theta$ & 12 & Dixit-Stiglitz elasticity of substitution \\
$\alpha$ & 0.75 & Calvo parameter \\
$\mu$ & 3.41 & Labor disutility \\
$\bar{b}$ & 0.4 & Debt-to-GDP ratio \\
$\bar{c}$ & 0.8 & Consumption-to-GDP ratio \\
$p_{11}$ & 0.95 & Probability to remain in regime 1 \\
$p_{22}$ & 0.95 & Probability to remain in regime 2 \\
\hline
\end{tabular}

When trend inflation is zero or 2\% (top panel of Figure 1), the well-known Davig and Leeper s (2007) long-run Taylor principle holds: a passive monetary policy, indeterminate in a static context, could return determinacy if, in the other regime, monetary policy is sufficiently aggressive. However, we get two important points as trend inflation goes to $4 \%$ or above. First, in line with Ascari and Ropele (2009), the Taylor principle breaks down because, to have determinacy, the central bank must

\footnotetext{
(2016).

${ }^{3}$ For additional details on the solution method and the stability criterion see the Online Appendix and Ascari et al.
} 

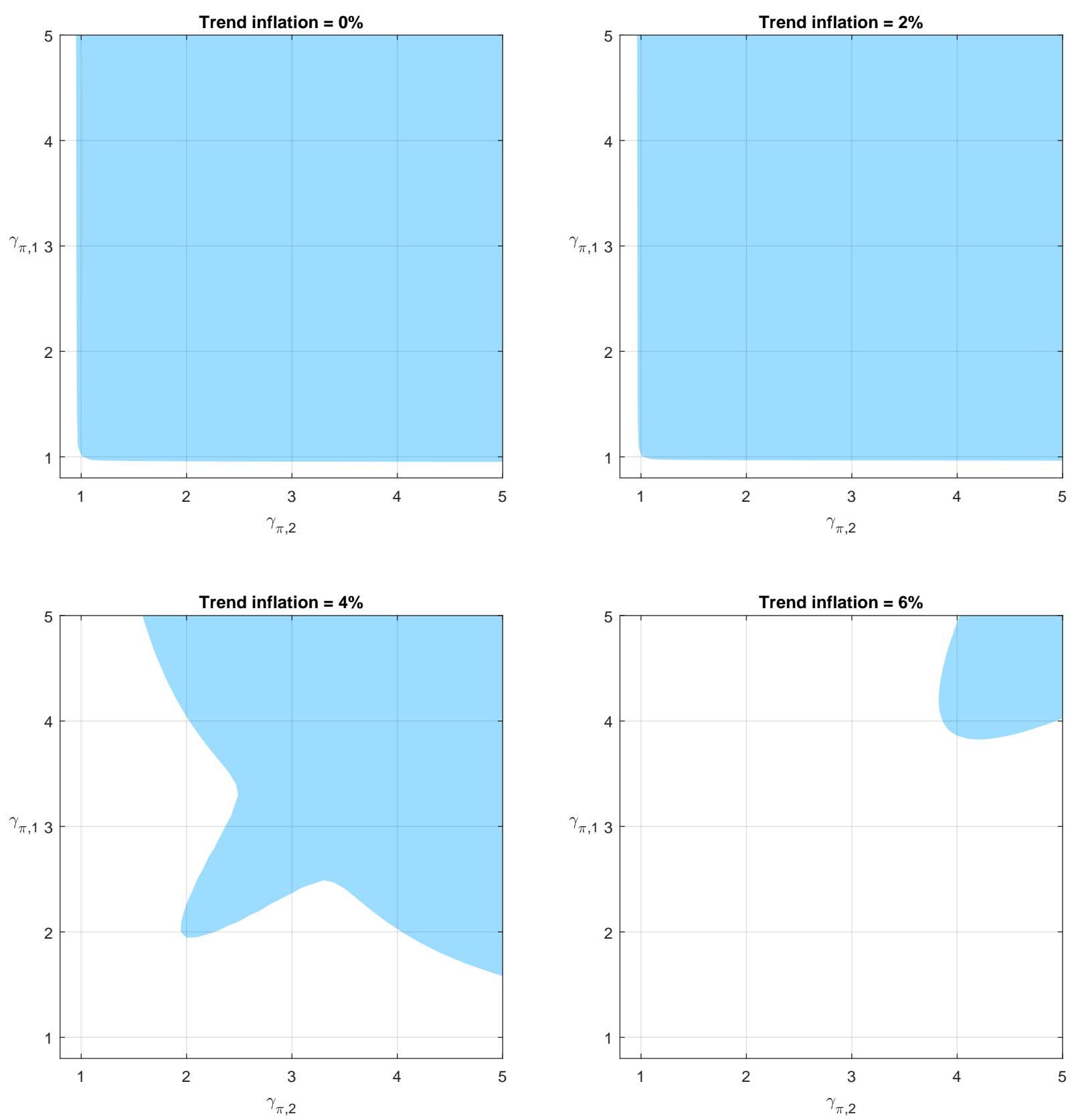

Figure 1: The monetary policy frontier for different levels of trend inflation.

Notes: Light blue area: unique solution; white area: indeterminacy. Transition probabilities are symmetric $\left(p_{11}=p_{22}=\right.$ $0.95)$ and fiscal policy is constantly passive $\left(\gamma_{\tau, 1}=\gamma_{\tau, 2}=0.2\right)$.

become increasingly hawkish $\left(\gamma_{\pi} \gg 1\right)$. Second, even the long-run Taylor principle breaks down. Therefore, with moderately high trend inflation (above $2 \%$ ) and a constantly passive fiscal authority, there is no chance to reach determinacy with a detour into passive monetary policy. Furthermore, for the parameter space in the figure, there would never be determinacy for trend inflation larger than $6 \%$.

The same comments apply when fiscal policy switches between active and passive, since monetary 
policy frontiers are qualitatively similar (see Figure A.1 in the Appendix) 4 So, with trend inflation at $4 \%$ or higher, one can never switch from $\mathrm{PM} / \mathrm{AF}$ to $\mathrm{AM} / \mathrm{PF}$, both determinate under fixed-coefficients, and maintain determinacy.

\section{Policy Implications}

Lack of flexibility Central bank's flexibility to accommodate short-run disturbances is a desirable aspect in the conduct of monetary policy, especially in periods of fiscal dominance when active inflation stabilization is de-emphasized to the benefit of financing the government budget. Our model shows that this flexibility is seriously impaired by high trend inflation since the central bank can never depart from an active monetary policy but rather, irrespective of the ongoing fiscal regime, it must be much more hawkish to get determinacy.

Monetary-fiscal coordination problems Davig and Leeper (2006) find policy coordination problems to be irrelevant because, despite periods of double active or passive monetary-fiscal mixes (respectively explosive and indeterminate under fixed-coefficients) the expectations of stable policy mixes are sufficient to get determinacy. We find this is not the case with trend inflation above $2 \%$ since determinacy is lost when the economy visits a double passive regime even if a stable policy mix is expected. The only possibility is switching between double active and an AM/PF regime (see Figure A.1).

From the Great Inflation to the Great Moderation High inflation in the "70s is often ascribed to an excessively accommodating central bank. Many believe that a switch to active monetary policy occurred in 1979; this implies the shift from a double passive (indeterminate in fixed-coefficient) policy mix, to a determinate $\mathrm{AM} / \mathrm{PF}$ one, that contributes decisively to the advent of a Great Moderation era. This result, valid both with fixed (Lubik and Schorfheide, 2004) or Markov-switching parameters (Davig and Leeper, 2007), hinges on the assumptions of constantly passive fiscal policy and zero trend inflation. Coibion and Gorodnichenko (2011) consider, more realistically, a positive inflation target in a fixed-coefficient setting. As the Taylor principle does not guarantee determinacy when trend inflation rises, they claim that the switch to determinacy at the end of the '70s was due, in large part, to the Volcker disinflation.

However, even fiscal policy could have switched from active to passive. The pre-Volcker era is found to be consistent with a PM/AF regime (Davig and Leeper, 2006, 2011; Sims, 2011; Bianchi

\footnotetext{
${ }^{4}$ We use parameter values consistent with the estimates in Davig and Leeper (2007) and Bianchi and Melosi (2013).
} 
and Melosi, 2013), with the increasing inflation due to lack of fiscal discipline. However, according to Bianchi and Ilut (2017), "If in the '70s agents had been confident about moving to the AM/PF regime, the Great Inflation would not have occurred".

When agents expect an $\mathrm{AM} / \mathrm{PF}$ regime in the future and trend inflation is low, we find determinacy under both the policy mixes that could have prevailed during the '70s. Provided monetary policy is not too passive, one can reach an $\mathrm{AM} / \mathrm{PF}$ mix and still have determinacy, both starting from a PM/PF mix (Figure 1) and from a PM/AF one (Figure A.1). However, with high trend inflation, as in the '70s, even agents' confidence on the advent in the early '80s of the AM/PF regime would not have avoided indeterminacy. As Coibion and Gorodnichenko (2011), we find a lower level of trend inflation to be a key factor behind the Great Moderation, irrespective of the ongoing fiscal regime.

Raising the inflation target If the Great Recession can be described by a PM/AF mix (Davig and Leeper, 2011), the proposal to increase the inflation target from $2 \%$ to $4 \%$ may be ill-advised, since it would impair the possibility to revert to an $\mathrm{AM} / \mathrm{PF}$ regime and preserve determinacy.

\section{Robustness}

The results of the paper are robust even if we alter the calibration of model parameters 5

Fiscal rule parameter. Fiscal policy is passive if $\gamma_{\tau, t}$ is in the range $(0.019,3.892)$. In our benchmark calibration we set $\gamma_{\tau, t}=0.2$, following Chung et al. (2007). However, results remain qualitatively unaffected even if we adopt $\gamma_{\tau, t}=0.1$, in line with Leeper and Walker (2012) and Bhattarai et al. (2016) for the post-Volcker period, or $\gamma_{\tau, t}=0.05$ as in Bhattarai et al. (2016) for the pre-Volcker period.

Price rigidity. A lower value of the Calvo parameter mitigates the effects of trend inflation. With a lower alpha $(\alpha=0.65)$ the detour is no longer possible for trend inflation above $4 \%$.

Dixit-Stiglitz elasticity of substitution. Our choice $\theta=12$ implies a steady-state markup of about $11 \%$, which is in line with estimated values in the literature (see, among others, Cogley and Sbordone, 2008; Galí, 2003). When trend inflation increases, the impossibility to maintain determinacy with a passive monetary detour is confirmed if a smaller $\theta$ is employed. However, some new (negligible) determinacy regions may appear without altering the main conclusion.

\footnotetext{
${ }^{5}$ To save space we do not report figures that are available from the authors upon request.
} 
Intertemporal elasticity of substitution in labor supply. Our calibaration assumes infinte intertemporal elasticity. With finite elasticity we find instead that a detour is no longer possible for trend inflation above $4 \%$.

Transition probabilities. Our results remain unchanged if we use lower $\left(p_{11}=p_{22}=0.93\right)$ or larger $\left(p_{11}=p_{22}=0.97\right)$ transition probabilities. If the two probabilities vary asymmetrically, results change according to their degree of divergence. With $p_{11}=0.95$ and $p_{22}=0.8$, the detour in the more transient regime is possible for every trend inflation up to 7\%. Asymmetric mean duration, in fact, expands the determinacy region in favour of the policy parameter corresponding to the less persistent regime: since deviations are expected to be short-lasting, monetary policy can deviate more decidedly into the passive territory. At the same time, monetary policy in the other regime should compensate being more active.

\section{Acknowledgements}

Alessandro Gobbi has received funding from the European Union under the Seventh Framework Programme FP7/2007-2013 Socio-economic Sciences and Humanities, Grant Agreement No. 612796 MACFINROBODS.

\section{References}

Ascari, G., A. Florio, And A. GobBi (2016): "Monetary and Fiscal Policy Interactions: Leeper (1991) Redux," Department of Economics Discussion Paper Series 788, University of Oxford.

Ascari, G. And T. Ropele (2009): "Trend inflation, Taylor Principle and Indeterminacy," Journal of Money, Credit and Banking, 41, 1557-84.

BALl, L. M. (2014): "The Case for a Long-Run Inflation Target of Four Percent," IMF Working Papers 14/92.

Bhattarai, S., J. W. Lee, And W. Y. Park (2014): "Inflation dynamics: The role of public debt and policy regimes," Journal of Monetary Economics, 67, 93-108.

(2016): "Policy Regimes, Policy Shifts, and U.S. Business Cycles," The Review of Economics and Statistics, 98, 968-983. 
Bianchi, F. And C. Ilut (2017): "Monetary/Fiscal Policy Mix and Agent's Beliefs," Review of Economic Dynamics, 26, 113-139.

Bianchi, F. AND L. Melosi (2013): "Dormant Shocks and Fiscal Virtue," in NBER Macroeconomics Annual 2013, Volume 28, 1-46.

Blanchard, O., G. Dell'Ariccia, and P. Mauro (2010): "Rethinking Macroeconomic Policy," Journal of Money, Credit and Banking, 42, 199-215.

Chung, H., T. Davig, And E. M. Leeper (2007): "Monetary and Fiscal Policy Switching," Journal of Money, Credit and Banking, 39, 809-842.

Cogley, T. And A. M. Sbordone (2008): "Trend Inflation, Indexation, and Inflation Persistence in the New Keynesian Phillips Curve," American Economic Review, 98, 2101-26.

Coibion, O. And Y. Gorodnichenko (2011): "Monetary Policy, Trend Inflation, and the Great Moderation: An Alternative Interpretation," American Economic Review, 101, 341-370.

Davig, T. And E. M. Leeper (2006): "Fluctuating Macro Policies and the Fiscal Theory," NBER Macroeconomics Annual, 21, 247-298.

(2007): "Generalizing the Taylor Principle," American Economic Review, 97, 607-635.

(2011): "Monetary-Fiscal Policy Interactions and Fiscal Stimulus," European Economic Review, 55, 211-227.

Farmer, R. E., D. F. Waggoner, And T. Zha (2009): "Understanding Markov-switching Rational Expectations Models," Journal of Economic Theory, 144, 1849 - 1867.

Florio, A. AND A. GobBi (2015): "Learning the Monetary/fiscal Interaction under Trend Inflation," Oxford Economic Papers, 67, 1146.

Foerster, A., J. F. RubioRamírez, D. F. Waggoner, and T. Zha (2016): "Perturbation Methods for Markovswitching Dynamic Stochastic General Equilibrium Models," Quantitative Economics, 7, 637-669.

Foerster, A. T. (2016): "Monetary Policy Regime Switches and Macroeconomic Dynamics," International Economic Review, 57, 211-230. 
Galí, J. (2003): New Perspectives on Monetary Policy, Inflation, and the Business Cycle, Cambridge University Press, vol. 3 of Econometric Society Monographs, 151197.

Leeper, E. M. (1991): “Equilibria under 'Active' and 'Passive' Monetary and Fiscal Policies," Journal of Monetary Economics, 27, 129-47.

Leeper, E. M. And T. B. Walker (2012): "Perceptions and Misperceptions of Fiscal Inflation," $255-299$.

Lubik, T. A. And F. Schorfheide (2004): "Testing for Indeterminacy: An Application to U.S. Monetary Policy," American Economic Review, 94, 190-217.

Sims, C. A. (2011): "Stepping on a Rake: The Role of Fiscal Policy in the Inflation of the 1970s," European Economic Review, 55, 48-56. 


\section{A Appendix}
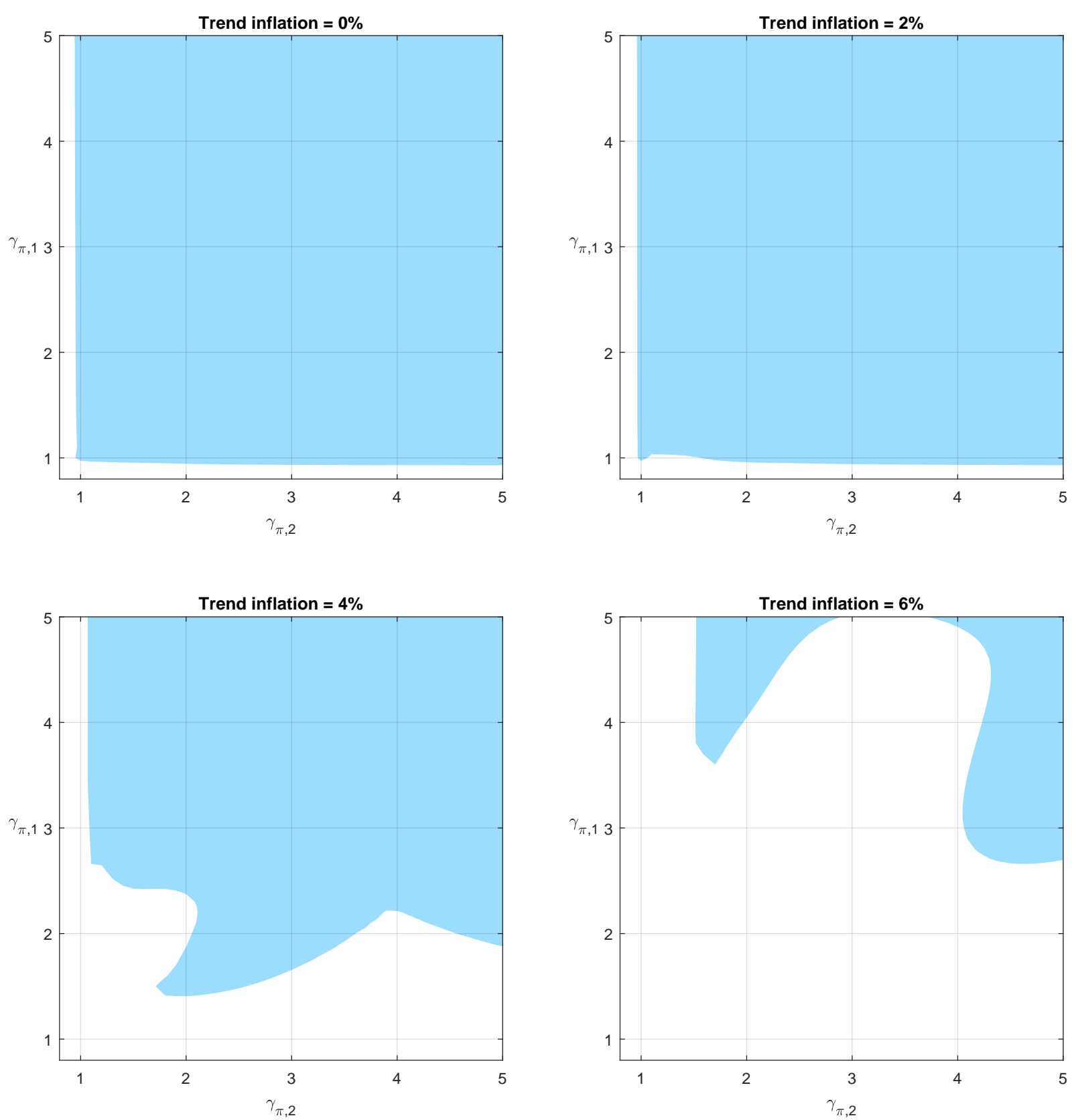

Figure A.1: The monetary policy frontier when fiscal policy switches.

Notes: Light blue area: unique solution; white area: indeterminacy. Transition probabilities are symmetric $\left(p_{11}=p_{22}=\right.$ $0.95)$ and fiscal policy is active in regime $1\left(\gamma_{\tau, 1}=0\right)$ and passive in regime $2\left(\gamma_{\tau, 2}=0.2\right)$. 